\title{
Albumin Mixed with Meconium Attenuates Pulmonary Dysfunction in a Newborn Piglet Model with Meconium Aspiration
}

\author{
PER ARNE TØLLØFSRUD, SVERRE MEDBØ, ANNE BEATE SOLÅS, \\ CHRISTIAN A. DREVON, AND OLA DIDRIK SAUGSTAD
}

Department of Pediatric Research [P.A.T., S.M., A.B.S., O.D.S.], Institute for Surgical Research [P.A.T., S.M., A.B.S.], the National Hospital, NO-0027, Oslo, Norway, and the Institute for Nutrition Research [C.A.D.], University of Oslo, PB 1046 Blindern, 0316 Oslo, Norway

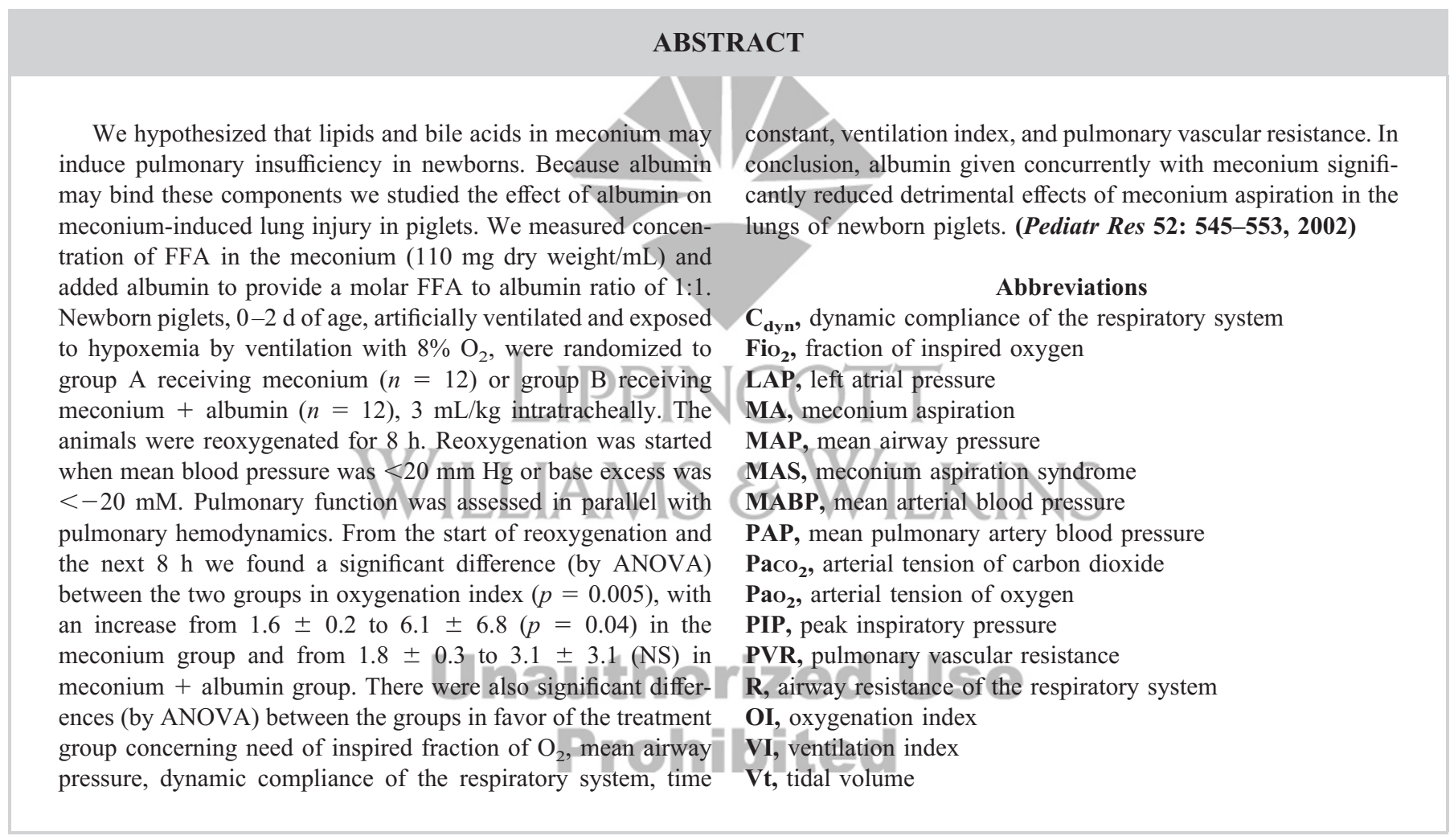

Meconium-stained amniotic fluid is frequently encountered during term as well as postterm deliveries. MAS has been found to occur in one tenth of these infants, with a mortality of 5 to $37 \%$ (median, 12\%) (1). Severe neonatal distress, pulmonary hypertension, and hypoxemia characterize MAS. The pathophysiology is complex and includes early as well as late effects. In the early phase meconium may obstruct the airways,

Received June 11, 2001; accepted May 30, 2002

Correspondence: Per Arne Tølløfsrud, M.D., Department of Pediatrics, Neonatal Intensive Care Unit, Sykehuset Buskerud- HF, 3004 Drammen, Norway; e-mail: p.a.tollofsrud@klinmed.uio.no

Supported by the Norwegian Foundation for Health and Rehabilitation, the Research Council of Norway, the Norwegian Council for Cardiovascular Disease, the Norwegian Women's Public Health Association, and Anders Jahres Fond.

DOI: 10.1023/01.PDR.0000028055.62744.10 leading to increased expiratory $\mathrm{R}$, inactivation of surfactant, decreased dynamic lung compliance, hypoxemia, and hypercapnia (2). The late phase is related to inflammatory changes, with airway and alveolar collapse secondary to chemical pneumonitis (3). Pulmonary interstitial inflammation is important for development of pulmonary hypertension $(4,5)$. One or more antenatal episodes of asphyxia injuring the lungs and pulmonary vasculature are also necessary in the development of MAS (6).

Meconium contains 75 to $80 \%$ water, and the solid phase includes lipids like FFA and water-soluble components like bile acids, in addition to fibers and inorganic molecules (7). In spite of the fact that MAS is both a serious and common illness in newborns, the treatment is not focused on etiological factors. 
In one study it was speculated that bile salt-induced accumulation of intracellular calcium in lung cells might contribute to the meconium-induced pneumonitis (5). Other authors have suggested that the FFA in meconium induce inflammation and lung injury $(8,9)$. FFA and especially oleic acid cause acute pulmonary injury in a well-described laboratory animal model promoting morphologic and cellular changes similar to human adult respiratory distress syndrome (10-13). FFA and bile acids in meconium also reduce surfactant function (14). It is known that albumin may bind lipids and bile acids as well as other detergents found in meconium. Albumin has an effect on surfactant-associated protein functional impairment. But during MA the inactivation of surfactant by meconium is so high that the given effect of albumin on the surfactant function is probably negligible. In the present study we examined whether albumin given concurrently with meconium could reduce the detrimental effects of MA in the lungs of newborn hypoxemic piglets.

\section{METHODS}

To test our hypothesis we performed a randomized study with newborn piglets subjected to hypoxemia, MA, and reoxygenation, in which we measured lung function and hemodynamic variables. The Norwegian Animal Experimental Board approved the experimental protocol, and the animals were handled in accordance with the European guidelines for the use of experimental animals.

Surgical preparation. Twenty-seven piglets $(\overline{0}-2 \mathrm{~d}$ of age $)$ were provided from a local farmer on the day of the experiments. Three piglets were excluded: one owing to anemia $(\mathrm{Hb}$ $<5 \mathrm{~g} / \mathrm{L})$ and a skin infection, one died of bleeding during surgery (both before randomization), and one owing to perforation of the bowl with peritonitis (meconium + albumin group).

Anesthesia was induced by halothane $4 \%$, which was then reduced to $1 \%$ and mixed with $30 \%$ oxygen, and continued with pentobarbital sodium $20 \mathrm{mg} / \mathrm{kg}$ and fentanyl $25-50 \mu \mathrm{g} / \mathrm{kg}$ i.v. as a bolus injection in an ear vein. For the rest of the experiment anesthesia was maintained with a continuous i.v. infusion of fentanyl $25-50 \mu \mathrm{g} / \mathrm{kg}$ per hour and midazolam 0.25 $\mathrm{mg} / \mathrm{kg}$ per hour i.v. Because fentanyl causes muscular rigidity, pancuronium bromide $0.2 \mathrm{mg} / \mathrm{kg}$ was given as a muscle relaxant when necessary. Lidocaine $1 \%$ was used as a local anesthetic.

A continuous i.v. infusion containing $0.7 \% \mathrm{NaCl}$ and $1.25 \%$ glucose was given at a rate of $10 \mathrm{~mL} / \mathrm{kg}$ per hour. Blood glucose was measured regularly with a Haemo-Glucotest (Boehringer Mannheim GmbH, Mannheim, Germany), and the infusion was adjusted to maintain blood glucose between 4 and $10 \mathrm{mM}$. A tracheotomy was performed for insertion of a 3.5-mm uncuffed Portex endotracheal tube, with a ligature around the tube and trachea to prevent air leakage. The right and left femoral arteries, right femoral vein, and right external jugular vein were cannulated with polyethylene catheters (Portex PE-50; inner diameter $0.58 \mathrm{~mm}$ ). Through a left-sided thoracotomy an 8-mm ultrasonic transit-time flow probe (Cardio Med, Medi-Stim, Oslo, Norway) was placed around the common pulmonary artery, proximal to the ductus arteriosus, for continuous recording of cardiac output and pulmonary artery blood flow. For measuring mean PAP and LAP, a catheter $0.8 \mathrm{~mm}$ OD (Vygon, Ecouen, France) was inserted into the pulmonary artery and left atrium, respectively. The chest wall was then closed in two layers. The catheters were flushed with heparinized saline $(4 \mathrm{U} / \mathrm{mL})$. The catheters in the left femoral artery, the right external jugular vein, the common pulmonary artery, and the left atrium were connected to straingauge transducers. MABP, central venous pressure, PAP, and LAP were recorded continuously on a Gould recorder TA 5000 (Gould Inc. Recording Systems, Cleveland, OH, U.S.A.). Skin electrodes monitored the heart rate. The right femoral artery catheter was used for blood sampling. Rectal temperature was maintained between $38^{\circ}$ and $40^{\circ} \mathrm{C}$ with a heating blanket or a radiant heating lamp. $\mathrm{Fio}_{2}$ and end-tidal $\mathrm{CO}_{2}$ were continuously monitored (Datex Normocap Oxy, Datex, Helsinki, Finland).

Meconium preparation. Meconium was obtained from the first stool of more than 20 healthy term babies of both sexes. It was pooled, rotary evaporated dry, irradiated with $\gamma$-rays (30 $\mathrm{kGy}$ ), and then diluted with sterile saline to a concentration of $110 \mathrm{mg} / \mathrm{mL}$. To achieve a homogeneous mixture, meconium was blended with a kitchen blender (Robert Bosch Hausgerate $\mathrm{GmbH}$, Munich, Germany). FFA in the meconium was measured. From the mixed meconium, $50 \mathrm{mg}$ of meconium was solubilized in $250 \mu \mathrm{L}$ of distilled water. FFA were extracted and separated by thin layer chromatography using hexanediethyl ether-acetic acid 80:20:1 as developing solvent according to Folch et al. (15) and Ranheim et al. (16). The FFA band was scraped out and redissolved in $500 \mu \mathrm{L}$ of isopropanol before analysis by the NEFA C-kit (catalog no. 994-75409E; Wako, Richmond, VA, USA). Isopropanol was used as a blank. From the meconium pool in this study the amount of FFA was measured to be $23.9 \mathrm{nmol} / \mathrm{mg}$ meconium dry weight. With the intention of a stoichiometric binding of FFA to albumin with a molar ratio of $1: 1,157 \mathrm{mg}$ BSA was added per milliliter of meconium solution, keeping the concentration of the meconium at $110 \mathrm{mg} / \mathrm{mL}$ (dry weight). The meconium mixture was stored in aliquots of $10 \mathrm{~mL}$ at $-20^{\circ} \mathrm{C}$ and slowly warmed up to $38^{\circ} \mathrm{C}$ before administration.

Experimental protocol. At the end of hypoxia, the piglets were randomly assigned to the meconium (control; $n=12$ ) or the meconium + albumin group $(n=12)$. The animals were subjected to hypoxemia and MA with or without albumin and reoxygenated for $8 \mathrm{~h}$. Hypoxemia was achieved by ventilation with a gas mixture of $8 \% \mathrm{O}_{2}$ in $\mathrm{N}_{2}$ (AGA, Oslo, Norway) until MABP fell below $20 \mathrm{~mm} \mathrm{Hg}$ or base excess was less than -20 $\mathrm{mM}$ (17). Immediately before the start of reoxygenation, the piglets received a bolus of $3 \mathrm{~mL} / \mathrm{kg}$ of meconium or meconium + albumin mixture via the endotracheal tube. The first $30 \mathrm{~s}$ after meconium instillation, piglets were ventilated with a Lærdal bag (Lærdal, Stavanger, Norway) at a rate of 60 breaths/min and a pressure that induced adequate chest expansion.

Ventilation. The animals were ventilated with a pressurecontrolled ventilator, Dräger Babylog 8000 plus (Drägerwerk $\mathrm{AG}$, Lübeck, Germany). Normoventilation $\left(\mathrm{PaCO}_{2} 4.5-6 \mathrm{kPa}\right)$ 
and a Vt of $10-15 \mathrm{~mL} / \mathrm{kg}$ were achieved by adjusting the PIP or ventilation rate. During surgery, stabilization of the piglets after surgery, and hypoxemia, the ventilation rate was set to 30 breaths $/ \mathrm{min}$. An inspiratory time of $0.4 \mathrm{~s}$ and a positive endexpiratory pressure of $3 \mathrm{~cm} \mathrm{H}_{2} \mathrm{O}$ were kept constant throughout the experiment. To maintain a constant $\mathrm{Vt}$ of $10-15 \mathrm{~mL} / \mathrm{kg}$ also after instillation of meconium, the piglets were put back on the ventilator with a PIP of $5 \mathrm{~cm} \mathrm{H}_{2} \mathrm{O}$ above baseline pressure, and the ventilation rate was increased to 60 breaths/ min. During the first 30 min of reoxygenation the $\mathrm{PaCO}_{2}$ was kept between 4.5 and $6 \mathrm{kPa}$ by altering the ventilation rate (in press). During the next $7.5 \mathrm{~h}$, normoventilation was obtained primarily by reducing the ventilation rate until a rate of 30 breaths/min was reached with a constant PIP. If the piglets were still hyperventilated, PIP was reduced. The initial $0.5 \mathrm{~h}$ of reoxygenation was performed with room air, but during the rest of the reoxygenation period $\mathrm{PaO}_{2}$ was kept above $7 \mathrm{kPa}$ in both groups by altering the $\mathrm{Fio}_{2}$. At the end of the study all animals were killed with a dose of $100 \mathrm{mg} / \mathrm{kg}$ pentobarbital i.v.

Blood samples. Samples for blood gas analyses were drawn from the femoral artery $30 \mathrm{~min}$ before the start of hypoxemia (baseline), at the start of hypoxemia, every 20 min during hypoxemia, at the start of reoxygenation, and $0.5,1,2,4,6$, and $8 \mathrm{~h}$ after reoxygenation. Temperature-corrected acid-base status was measured with a Bloodgas Analyzer 860 (Ciba Corning Diagnostics Corp. Medfield, MA, U.S.A.). Hb was measured at baseline and at the end of reoxygenation with a CO-Oximeter 482 (Instrumentation Laboratory, Lexington, MA, U.S.A.). $\mathrm{C}$-reactive protein and leukocyte counts in blood were measured at baseline and at the end of reoxygenation. We replaced the withdrawn blood with a 3 -fold volume of saline.

Samples for measuring plasma endothelin- 1 were drawn from the femoral artery at baseline, at the end of hypoxia, and at the end of reoxygenation. Handling of the samples and analyses were performed as described previously in detail (18).

Lung function data measurements and calculation. The Dräger Babylog 8000 plus was used to measure airway pressure and flow. MAP was measured at the Y-piece. The lung volume was calculated as a function of flow. The ventilator performed the calculations of $\mathrm{C}_{\mathrm{dyn}}$ and $\mathrm{R}$ of the respiratory system using the ventilation curve for pressure, flow, and volume and a linear regression method that measured 120 values per second (19). According to a study by Roske et al. (20), the accuracy of the volume measurements made by the Babylog 8000 is $5.5 \pm 1.5 \%$. Lung function was recorded at the same times as measurements of blood gases and acid-base status. OI was calculated by the formula MAP $\left(\mathrm{cm} \mathrm{H}_{2} \mathrm{O}\right) \times$ $\mathrm{Fio}_{2} / \mathrm{PaO}_{2}$ (Torr) $\times 100$ and VI by: $\mathrm{PCO}_{2}(\mathrm{~mm} \mathrm{Hg}) \times$ ventilation rate $\times$ PIP $\left(\mathrm{cm} \mathrm{H}_{2} \mathrm{O}\right) / 1000$.

Hemodynamic data collection and analysis. MABP, PAP, LAP, cardiac output, and heart rate were logged into a computer using software specially developed for this purpose (Work Bench PC for Windows, Sunnyvale, CA, U.S.A.), using a logging frequency of $0.2 \mathrm{~Hz}$. Before statistical evaluation the mean values for the logged and calculated variables for each animal were calculated in blocks of $30 \mathrm{~s}$ (mean of six samples) to represent each time. At the start of reoxygenation $10 \mathrm{~s}$ (mean of two samples) were used.
Statistics. All values are given as mean $\pm \mathrm{SD}$. Two-sided $p$ values $<0.05$ were considered significant. A paired $t$ test was used when comparing two times in the same group. When comparing two groups an unpaired $t$ test was used. Repeated analyses during a time course were performed by repeatedmeasures ANOVA to investigate the effect of time, group, and group-by-time interactions in the two groups. The groups are compared from the start to $8 \mathrm{~h}$ of reoxygenation. In some cases $\log$ transformation was performed to meet the requirement of the statistical analyzes. All analyzes were done with StatView 5.0 (Abacus Concepts, Inc., Berkeley, CA, U.S.A.). A graphics program (Graphpad Prism, 2.01, Graphpad Software, San Diego, CA, U.S.A.) was used to produce the graphs.

\section{RESULTS}

There were no significant differences between the groups in age, body weight, $\mathrm{Hb}, \mathrm{C}$-reactive protein, or blood leukocyte counts at baseline. The mean hypoxemia time in the meconium and meconium + albumin groups were $74 \pm 34$ and $59 \pm 20$ min, respectively $(p=0.18)$. At the start of reoxygenation there were no differences between the two groups in mean base excess, MABP and other hemodynamic variables, lung function, or calculated values.

Oxygenation and ventilation. Oxygen requirement $\left(\mathrm{Fio}_{2}\right)$ (Fig. 1A) increased from 0.5 to $8 \mathrm{~h}$ of reoxygenation in the meconium group, but not in the meconium + albumin group, with a significant group-by-time difference $(p=0.008)$. The first $0.5 \mathrm{~h}$ of reoxygenation was room air reoxygenation in both groups.

The OI (Fig. $1 B$ ) increased significantly from $1.6 \pm 0.2$ at start of reoxygenation to $6.1 \pm 6.8(p=0.04)$ at $8 \mathrm{~h}$ of reoxygenation in the meconium group and only from $1.4 \pm 0.2$ to $3.1 \pm 3.1(\mathrm{NS})$ in the meconium + albumin group. There was a significant group-by-time difference between the two groups during reoxygenation $(p=0.005)$.

Furthermore, the MAP (Fig. 1C) increased significantly by $59 \%$ during reoxygenation in the meconium group from $5.9 \pm$ 0.3 to $10.0 \pm 4.0 \mathrm{~cm} \mathrm{H}_{2} \mathrm{O}(p=0.005)$, whereas in the meconium + albumin group this increase was $21 \%$, from 6.1 \pm 1.2 to $7.7 \pm 2.3 \mathrm{~cm} \mathrm{H}_{2} \mathrm{O}(p=0.05)$. There was a significant group-by-time difference between the two groups $(p=0.007)$.

The VI (Fig. 1D) increased significantly in the meconium $(p$ $=0.001)$ and the meconium + albumin $(p=0.01)$ groups during reoxygenation, but with less increase in the meconium + albumin group and a significant group-by-time difference between the groups $(p=0.01)$.

The mean $\mathrm{PaO}_{2}$ values showed no difference between the two groups during reoxygenation (Table 1), but the mean $\mathrm{PaCO}_{2}$ values were significantly higher in the meconium group than the meconium + albumin group during reoxygenation (Table 1).

During reoxygenation both PIP and respiration rate were lower in the meconium + albumin group compared with the meconium group, but the differences were not significant (Table 2). The $\mathrm{Vt}$ in the meconium + albumin group was higher than in the meconium group without significant difference (Table 2). 
A

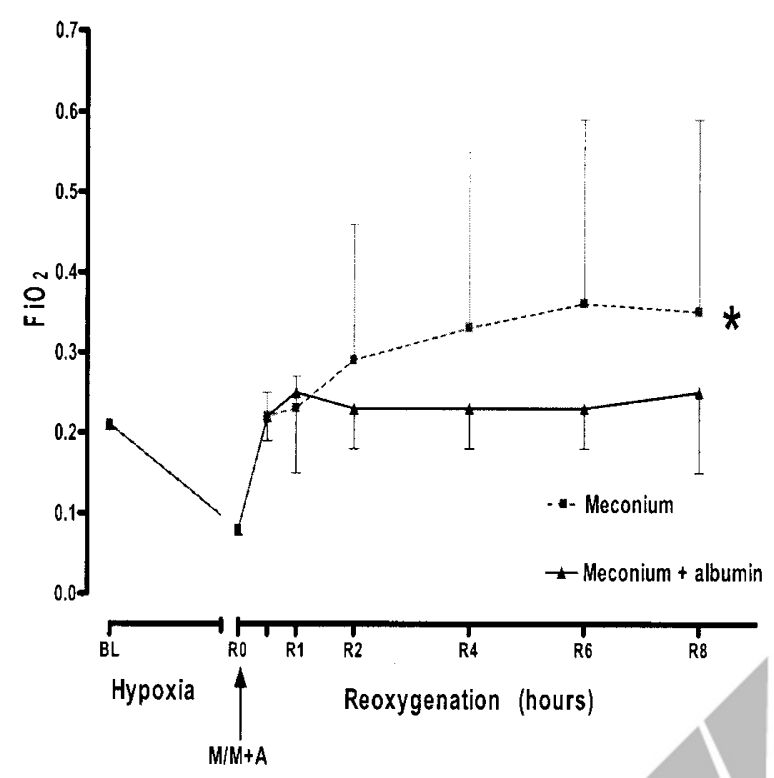

c

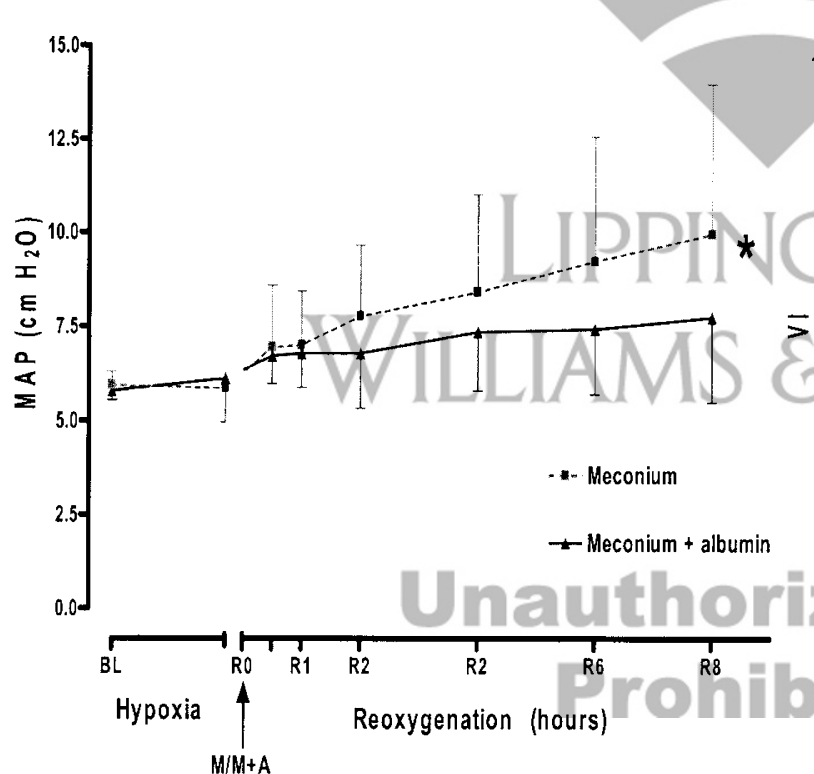

B

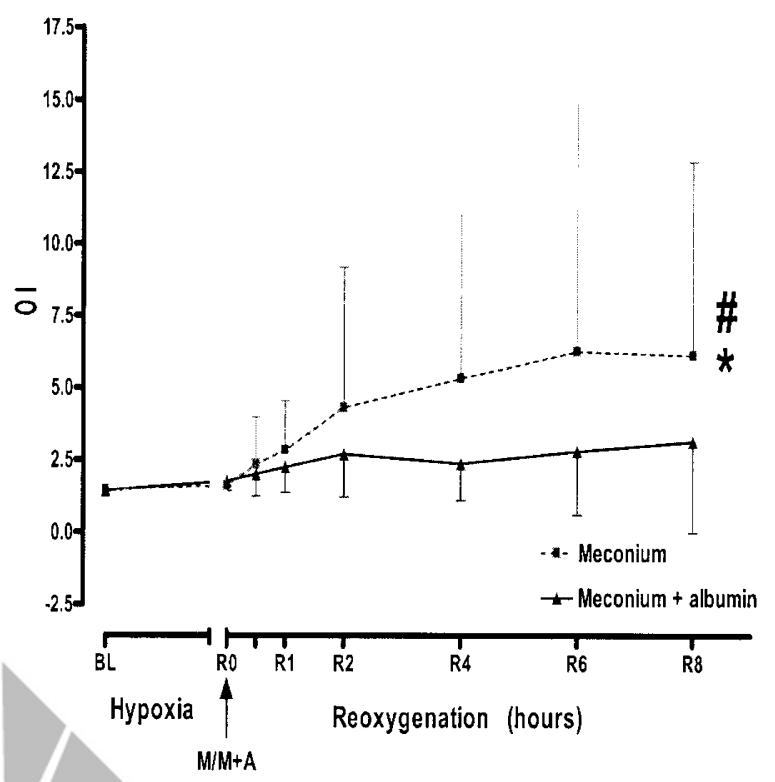

D

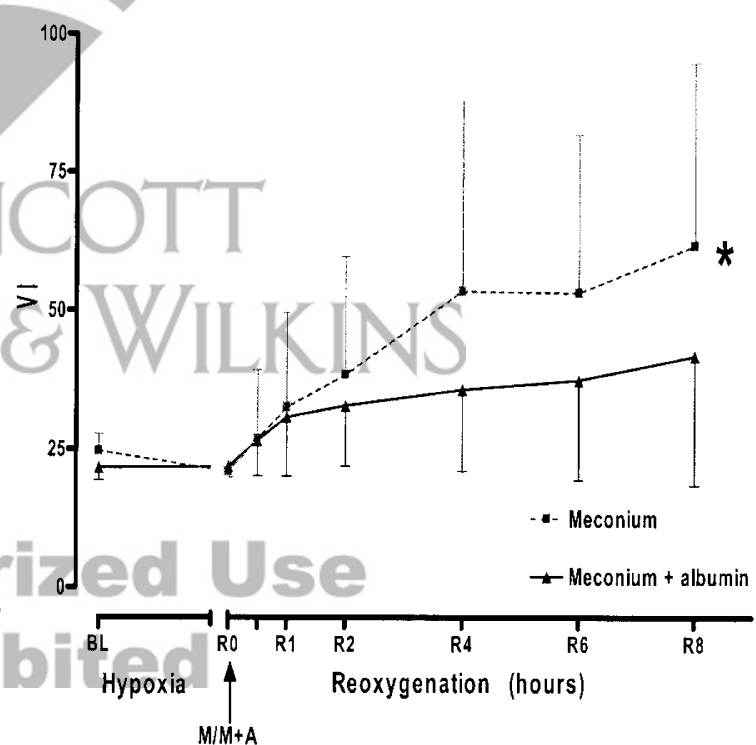

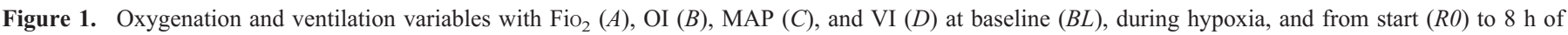

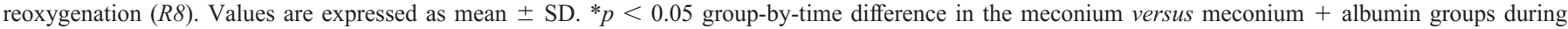
reoxygenation. $\# p<0.05 \mathrm{R} 0$ versus $\mathrm{R} 8$ in the meconium group.

Table 1. $\mathrm{PaCO}_{2}$ and $\mathrm{PaO}_{2}$ in blood from start of reoxygenation to $8 \mathrm{~h}$ of reoxygenation in the meconium and meconium + albumin groups

\begin{tabular}{clcrrrrrr}
\hline Variable & Group & R0 & R0.5 h & R1 h & R2 h & R4 h & R6 h & R8 h \\
\hline $\mathrm{PaCO}_{2}(\mathrm{kPa})^{*}$ & $\mathrm{Mec}$ & $4.8 \pm 0.1$ & $4.3 \pm 0.1$ & $5.3 \pm 0.2$ & $5.4 \pm 0.2$ & $6.1 \pm 0.2$ & $5.7 \pm 0.3$ & $6.0 \pm 0.2$ \\
& $\mathrm{Mec}+\mathrm{A}$ & $5.0 \pm 0.1$ & $4.4 \pm 0.1$ & $4.8 \pm 0.2$ & $5.3 \pm 0.2$ & $5.1 \pm 0.1$ & $5.2 \pm 0.1$ & $5.4 \pm 0.2$ \\
$\mathrm{PaO}_{2}(\mathrm{kPa})$ & $\mathrm{Mec}$ & $3.9 \pm 0.1$ & $9.8 \pm 0.7$ & $8.2 \pm 0.5$ & $8.6 \pm 0.5$ & $8.9 \pm 0.5$ & $9.5 \pm 0.7$ & $9.2 \pm 0.7$ \\
& $\mathrm{Mec}+\mathrm{A}$ & $3.7 \pm 0.1$ & $10.3 \pm 0.7$ & $10.4 \pm 1.0$ & $8.8 \pm 0.4$ & $10.3 \pm 0.7$ & $9.4 \pm 0.6$ & $9.4 \pm 0.4$ \\
\hline
\end{tabular}

Values are expressed as mean $\pm \mathrm{SD} . * p=0.03$ group difference between the meconium and meconium + albumin groups from $\mathrm{R} 0$ to $\mathrm{R} 8 \mathrm{~h}$. Abbreviations used: $\mathrm{R}$, reoxygenation; Mec, meconium; A, albumin.

Lung function. In the meconium + albumin group, $\mathrm{C}_{\mathrm{dyn}}$ (Fig. $2 A$ ) remained unchanged, $1.30 \pm 0.3$ to $1.16 \pm 0.3 \mathrm{~mL} / \mathrm{kPa}(\mathrm{NS})$ from start to $8 \mathrm{~h}$ of reoxygenation. In the meconium group $\mathrm{C}_{\mathrm{dyn}}$ decreased significantly from $1.20 \pm 0.2$ to $0.84 \pm 0.2 \mathrm{~mL} / \mathrm{kPa}(p$ $=0.001)$. There was a significant group-by-time difference $(p=$ 0.006 ) between the groups during reoxygenation. 
Table 2. Vt, PIP, and respiratory rate from baseline to $8 \mathrm{~h}$ of reoxygenation in the meconium and meconium + albumin groups

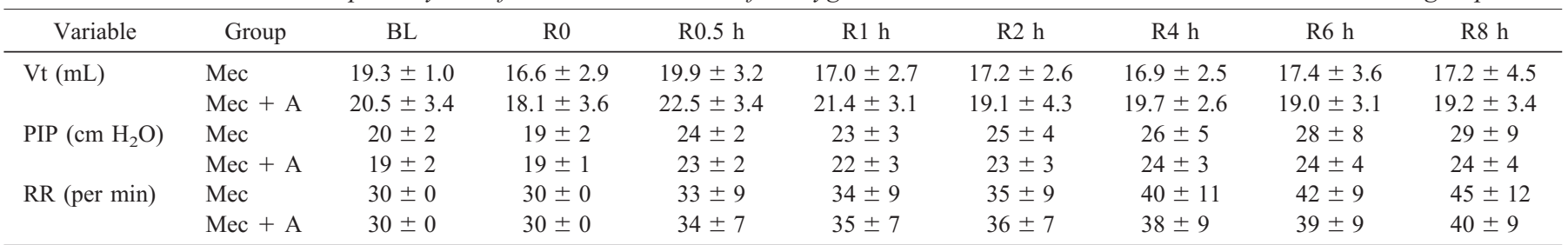

Values are expressed as mean $\pm \mathrm{SD}$. There were no significant differences between the groups in any of the variables.

Abbreviations used: BL, baseline; R, reoxygenation; RR, respiratory rate; Mec, meconium; A, albumin.

The time constant of the respiratory system (Fig. $2 B$ ) decreased significantly in the meconium group from $116 \pm 25$ to $98 \pm 22 \mathrm{~ms}(p=0.01)$, but not in the meconium + albumin group, from $113 \pm 41$ to $115 \pm 38 \mathrm{~ms}$ (NS), during the reoxygenation period. There was a significant group-by-time difference between the groups $(p=0.04)$.

$\mathrm{R}$ (Fig. 2C) increased significantly during the first hour of reoxygenation in both the meconium and the meconium + albumin groups. In the meconium group this increase was larger and there was a significant group difference between the two groups in this period $(p=0.01)$. During the rest of the reoxygenation there were no significant differences between the two groups.

Hemodynamics. During the first $0.5 \mathrm{~h}$ of reoxygenation there was a significant increase in MABP in the two groups (Fig. 3A). However, MABP in the meconium + albumin group increased to a higher level and remained at a higher lever throughout the reoxygenation, with a significant group difference $(p=0.005)$ between the groups.

The pulmonary artery blood flow (Fig. $3 B$ ) decreased during hypoxemia and returned to baseline level after $0.5 \mathrm{~h}$ of reoxygenation. During the rest of the reoxygenation period the pulmonary artery blood flow remained at baseline level with no difference between the groups.

PAP (Fig. 3C) increased significantly in the meconium group from $26 \pm 6$ to $37 \pm 10 \mathrm{~mm} \mathrm{Hg}(p=0.01)$ from start to $8 \mathrm{~h}$ of reoxygenation. In the meconium + albumin group PAP increased only from $26 \pm 9$ to $32 \pm 8 \mathrm{~mm} \mathrm{Hg}$ (NS). Furthermore, there were no differences between the two groups during the reoxygenation period.

The PVR (Fig. 3D) increased during hypoxemia in both groups. After start of reoxygenation PVR reached baseline level after $30 \mathrm{~min}$ in the meconium + albumin group. In the meconium group PVR remained elevated, and at $8 \mathrm{~h}$ of reoxygenation PVR was significant higher in the meconium $(p=$ 0.03 ) than in the meconium + albumin group. From $30 \mathrm{~min}$ to $8 \mathrm{~h}$ of reoxygenation there was also a significant group difference between the two groups $(p=0.03)$.

Plasma endothelin-1 (Table 3) decreased during hypoxemia as demonstrated earlier by our group $(18,21)$. During reoxygenation plasma endothelin-1 is above baseline in both groups $(p=0.002)$. Plasma endothelin-1 increased $38 \%$ in the meconium and $24 \%$ in the meconium + albumin group throughout the reoxygenation period. The difference between the groups is not significant, and there was no correlation between plasma endothelin-1 and PVR.

\section{DISCUSSION}

Our present results indicate that albumin given concurrently with meconium reduces pulmonary insufficiency after MA in piglets exposed to hypoxemia and then reoxygenated. Albumin improved oxygenation, prevented a decrease in elasticity of the lungs, and reduced the PVR.

Meconium may alter airway $\mathrm{R}$ by a number of mechanisms such as mechanical obstruction, reflex alteration in airway muscle cell tone, or production of bronchoreactive agents (22). In an in yitro study in rats, Collins et al. (22) found that the direct action of meconium on tracheal smooth muscle, which in part may be mediated by FFA, did not appear to contribute significantly to the increased airway tone. The airway $\mathrm{R}$ in our study did not differ between the groups except for the first hour after instillation of meconium. According to the findings of Collins et al. (22) blocking of FFA in meconium will not influence the airway R during MA. In our study a possible increase in Viscosity of the meconium caused by albumin might reduce mechanical obstruction in the airways, and explain the lower airway $\mathrm{R}$ in the meconium + albumin group during the first hour of reoxygenation.

After the early phase with meconium obstruction as the dominant feature (2), MA is associated with alveolar as well as parenchymal edema (1), which could be caused by detergents like lipids or bile acids found in meconium. Binding of FFA or bile acids may limit the amount of detergents promoting inflammation, leading to decreased vascular permeability and reduction in alveolar and lung parenchymal edema. In a study by Soukka et al. (4), methylprednisolone decreased lung edema and improved oxygenation after MA. Khan and colleagues (23) found after MA that dexamethasone improved pulmonary compliance and decreased oxygen requirement. Adding albumin to meconium seems to give similar results as found in these two studies.

The observed reduction in elasticity of the lungs in the meconium group compared with the meconium + albumin group may be explained either by a reduction of alveolar and parenchymal edema or by less inactivation of surfactant. Surfactant activity per se is inhibited by FFA, bilirubin, bile acids, and albumin (14, 24-28). Wang and Notter (25) demonstrated that mixtures of albumin and FFA actually had a reduced inhibitory effect on surfactant activity compared with FFA alone. Albumin effectively limits the formation of the film structure on which lipid inhibitors act, reducing the potential 

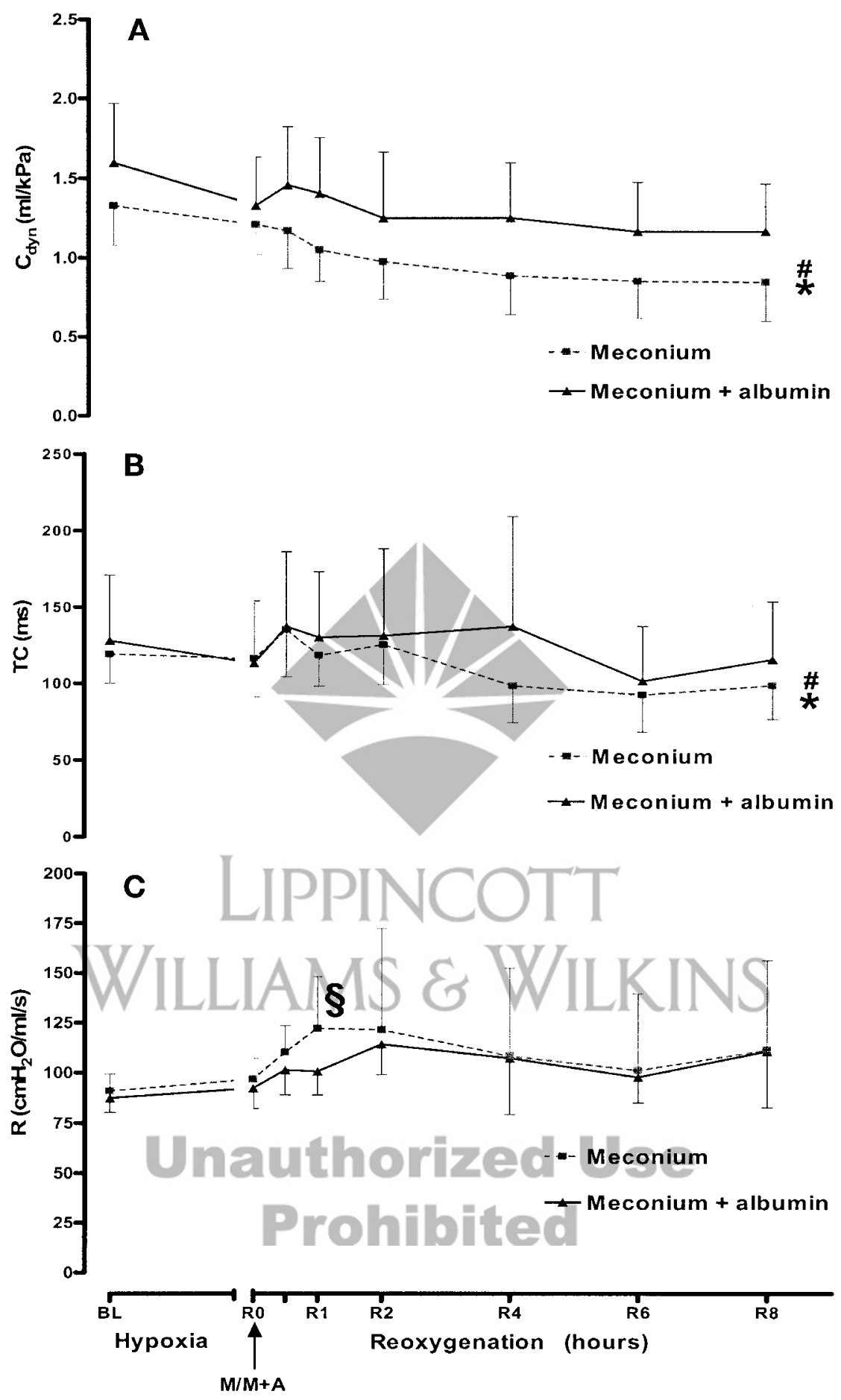

Figure 2. Lung function variables with $\mathrm{C}_{\mathrm{dyn}}(A)$, time constant of the respiratory system $(\mathrm{Tc} ; B)$, and $\mathrm{R}(C)$ at baseline $(B L)$, during hypoxia, and from start $(R 0)$ to $8 \mathrm{~h}$ of reoxygenation $(R 8)$. Values are expressed as mean $\pm \mathrm{SD} .{ }^{*} p<0.05$ group-by-time difference in the meconium versus meconium + albumin groups during reoxygenation. $\# p<0.05 \mathrm{R} 0$ versus $\mathrm{R} 8$ in the meconium group. $\$ p<0.05$ group difference in the meconium versus meconium + albumin groups from $\mathrm{R} 0$ to $1 \mathrm{~h}$ of reoxygenation.

synergy between albumin and FFA. The inhibitory effect of this mixture was similar to that found for albumin alone (25).

In newborn piglets we have previously shown that MA after hypoxemia leads to increase in PAP (29). In 10-wk-old pigs Soukka et al. (4) have reported that methylprednisolone given i.v. before insufflation of meconium attenuates PAP and PVR. In the present study albumin given together with meconium reduced the increase in PAP and prevented the increase in
PVR. The inflammatory response to meconium leads to increased airway levels of various eicosanoids. These vasoactive mediators may play a role in the pulmonary vasoconstriction frequently seen in MAS (1). The principal anti-inflammatory action of corticosteroids is suggested to reduce eicosanoid production by impairing phospholipase activation $(30,31)$. The mechanism of action of albumin in the present study is not obvious, but we can speculate that albumin reduces the pro- 
A
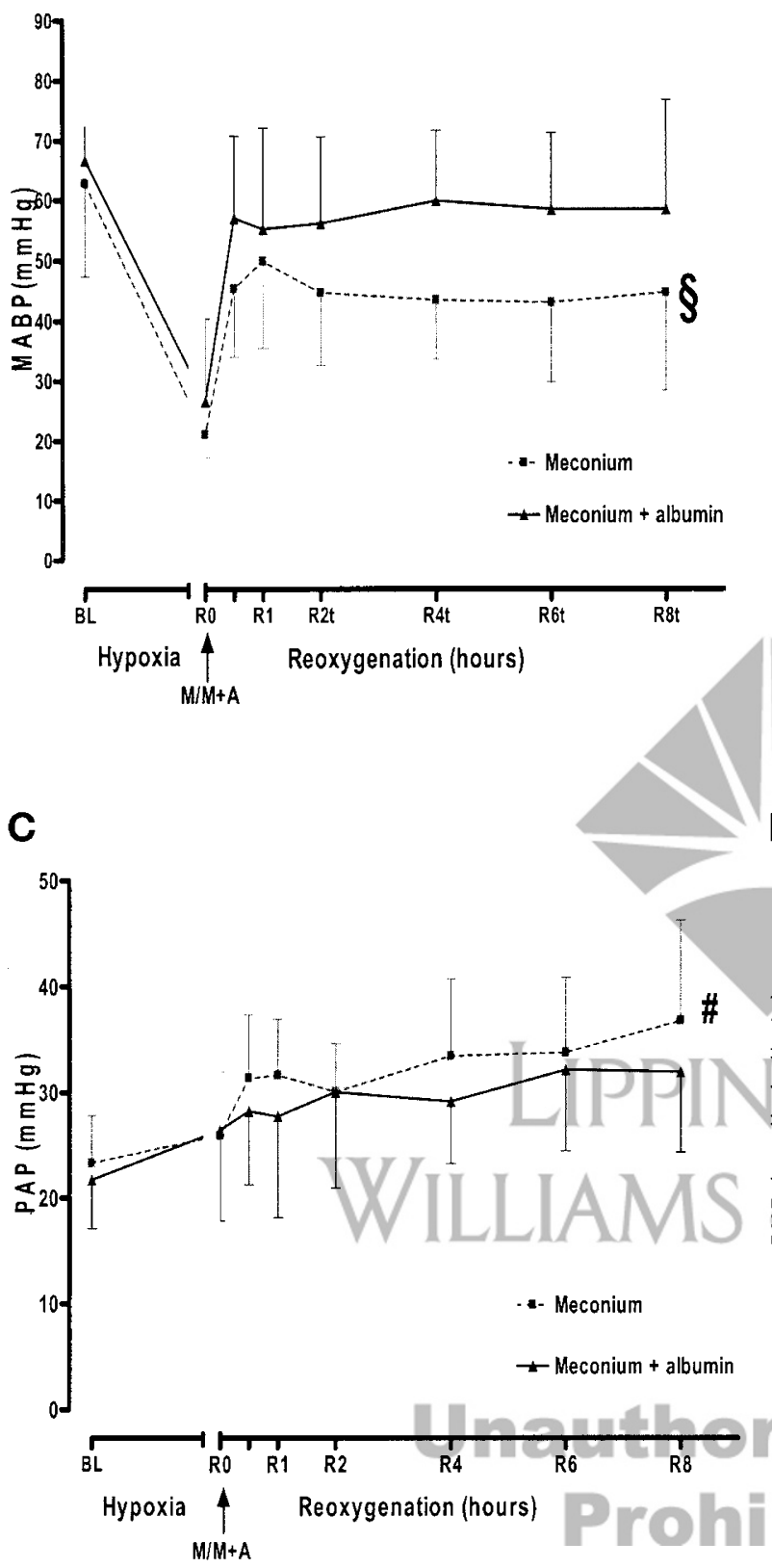

B

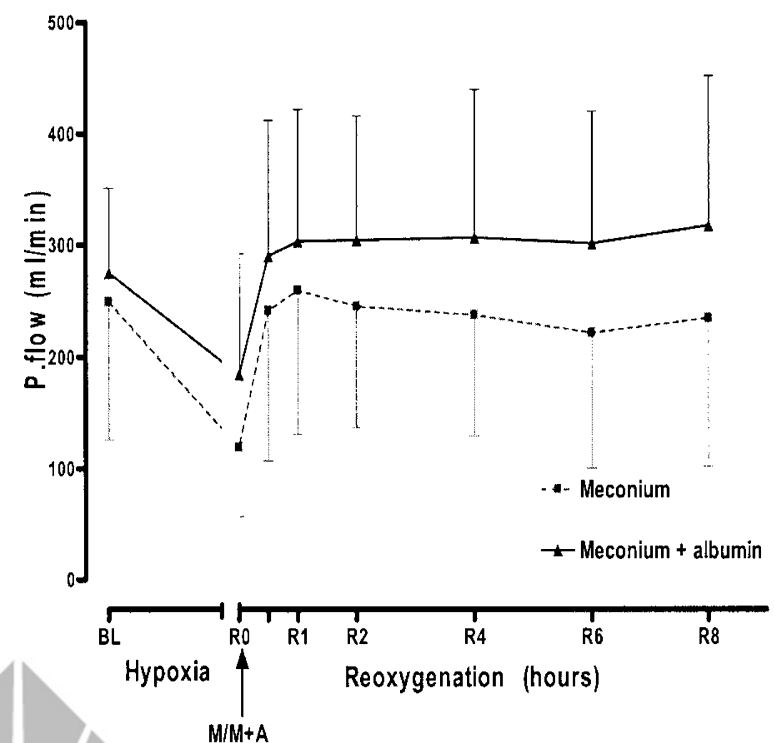

Figure 3. Hemodynamic variables with $\operatorname{MABP}(A)$, pulmonary artery blood flow (P.flow; $B)$, mean PAP $(C)$, and PVR $(D)$ at baseline $(B L)$, during hypoxia, and from start $(R 0)$ to $8 \mathrm{~h}$ of reoxygenation $(R 8)$. Values are expressed as mean $\pm \mathrm{SD}$. $\S p<0.05$ group difference in the meconium versus meconium + albumin groups during reoxygenation. $\# p<0.05$ R0 versus $\mathrm{R} 8$ in the meconium group. ${ }^{* *} p<0.05$ meconium versus meconium + albumin groups at $\mathrm{R} 8$.

Table 3. Plasma endothelin-1 from start of reoxygenation to $8 \mathrm{~h}$ of reoxygenation in the meconium and meconium + albumin groups

\begin{tabular}{ccccccc}
\hline Group & BL & R0 & R1 h & R2 h & R6 h \\
\hline Mec & $1.8 \pm 0.5$ & $1.5 \pm 0.5$ & $2.2 \pm 0.6^{*}$ & $2.4 \pm 0.8^{*}$ & $2.4 \pm 0.9^{*}$ & $2.4 \pm 1.0^{*}$ \\
$\mathrm{Mec}+\mathrm{A}$ & $1.8 \pm 0.6$ & $1.6 \pm 0.7$ & $2.3 \pm 0.6^{*}$ & $2.3 \pm 0.5^{*}$ & $2.1 \pm 0.6^{*}$ & $2.1 \pm 0.7^{*}$ \\
\hline
\end{tabular}

Values are expressed as mean $\pm \mathrm{SD} .{ }^{*} p<0.05 \mathrm{BL}$ versus the reoxygenation period in both groups.

Abbreviations used: BL, baseline; R, reoxygenation; Mec, meconium; A, albumin.

duction of the vasoactive mediators by binding of inflammation-evoking substances in the meconium.

Adding albumin to the meconium in our model reduced the detrimental effects on the lungs caused by meconium, which are similar to the lung injury promoted by oleic acid in laboratory models. It is likely that FFA plays a role in devel- opment of MAS and that binding of FFA is one way to prevent MAS. The pathogenesis of FFA-induced lung injury is, however, not understood. In one study in sheep, arterial hypoxemia, pulmonary arterial hypertension, and increased pulmonary edema were found after oleic acid-induced injury (13). This lung injury was unaffected by profound depletion of leukocytes 
or platelets, and it was not influenced by pharmacologic intervention with methylprednisolone. Moreover, in a rat model reduced pulmonary inflammation and restored lung compliance after steroid therapy were demonstrated (32). In another study Beilman (12) found that the direct toxicity of oleic acid to pulmonary vascular endothelial cells is an important pathologic factor in oleic acid-induced lung injury.

Meconium contains mainly palmitate, stearate, and oleate acids in an approximate 2:1:1 ratio and generally constitutes at least $50 \%$ of the total FFA content. The rest of FFA in meconium includes arachidonic acid, behenic acid, and longchain fatty acids greater than 22-carbon length (9). The total FFA content in meconium varies by as much as 9-fold among samples (9). To avoid the influence this variability might have on our results, we pooled the meconium from $>20$ babies.

Also bile injected intratracheally in rabbits and pigs produces severe pulmonary edema, atelectasis, and focal hemorrhage $(33,34)$. Oelberg et al. (5) found bile salt to be cytotoxic for pneumocytes, speculating that this may contribute to the pathogenesis of meconium aspiration pneumonitis. It is not possible from the present study to distinguish between FFA and bile acids as the most important substance damaging the lung after MA.

Although mean $\mathrm{PacO}_{2}$ in both groups was within normal range during the experiment, during reoxygenation mean $\mathrm{PCO}_{2}$ was significantly higher in the meconium than the meconium + albumin group (Table 1). As VI (Fig. 1D) also was significantly higher in the meconium group, we think that mean $\mathrm{PCO}_{2}$ was higher in the meconium group because of increased lung injury. Furthermore, there were no significant differences in $\mathrm{Vt}$ and ventilatory settings between the groups (Table 2). The slightly higher ventilatory settings in the meconium group were not enough to contribute to and potentiate the evolving injury.

Endothelin-1 is involved in the regulation of the pulmonary vascular tone $(35,36)$. The decrease in plasma endothelin-1 during hypoxemia is in agreement with previous studies from our group $(18,21)$. During reoxygenation, we previously have shown that plasma endothelin-1 returns to baseline within 30 min to $2 \mathrm{~h}$ of reoxygenation. In this study, however, plasma endothelin-1 is significantly greater than baseline throughout reoxygenation in both groups, with a tendency for higher values in the meconium than the meconium + albumin groups from $2 \mathrm{~h}$ of reoxygenation. This tendency may be in agreement with the increased PAP and PVR in the meconium group during reoxygenation.

The main mechanism whereby the meconium + albumin combination results in a different outcome compared with meconium alone most likely has to do with the binding and inactivation of lipid and bile acids in meconium by albumin, reducing the inflammatory action of these substances. Further studies are planned to clarify this.

In a clinical setting albumin would have to be administrated after the aspiration of meconium, and the albumin-meconium interaction could be different than in the present study. We believe postmeconium albumin would give similar results if albumin were administrated as soon as possible after MA and in a concentration high enough to bind lipids and bile acids in the meconium. A study is under preparation.
The severity of the lung injury used in our study is moderate. The severity of MAS does not only depend on the amount of meconium aspirated, but also the asphyxia-induced lung injury and increased vascular hyperreactivity of the pulmonary vessels after repeated or long-standing prelabor hypoxemia (3739). Further studies are needed to investigate the effect of albumin on MAS in models using repeated hypoxemia and instillation of lager amounts of meconium.

\section{CONCLUSIONS}

In conclusion, we found significant differences between animals given meconium or meconium + albumin regarding $\mathrm{FiO}_{2}$, OI, MAP, $\mathrm{C}_{\mathrm{dyn}}$, time constant, VI, and PVR. The fact that all these important variables favor the meconium + albumin group leads us to conclude that albumin given concurrently with meconium significantly attenuates meconium-induced lung injury. Albumin likely binds and reduces the action of lipids or bile acids in meconium, leading to reduced inflammation. This may represent a new principle in treating newborn babies with MA.

Acknowledgments. The authors thank Thore Egeland for valuable statistical advice and Anne Randi Alvestad for excellent laboratory assistance.

\section{REFERENCES}

1. Cleary GM, Wiswell TE 1998 Meconium-stained amniotic fluid and the meconium aspiration syndrome: an update. Pediatr Clin North Am 45:511-529

2. Tran N, Lowe C, Sivieri EM, Shaffer TH 1980 Sequential effects of acute meconium obstruction on pulmonary function. Pediatr Res 14:34-38

3. Tyler DC, Murphy J, Cheney FW 1978 Mechanical and chemical damage to lung tissue caused by meconium aspiration. Pediatrics 62:454-459

4. Soukka H, Halkola L, Aho H, Rautanen M, Kero P, Kaapa P 1997 Methylprednisolone attenuates the pulmonary hypertensive response in porcine meconium aspiration. Pediatr Res 42:145-150

5. Oelberg DG, Downey SA, Flynn MM 1990 Bile salt-induced intracellular $\mathrm{Ca}^{++}$ accumulation in type II pneumocytes. Lung 168:297-308

6. Katz VL, Bowes Jr WA 1992 Meconium aspiration syndrome: reflections on a murky subject [see comments]. Am J Obstet Gynecol 166:171-183

7. Harris J 1978 Meconium in health and disease. Br Med Bull 34:75-78

8. Davey AM, Becker JD, Davis JM 1993 Meconium aspiration syndrome: physiological and inflammatory changes in a newborn piglet model. Pediatr Pulmonol 16:101108

9. Terasaka D, Clark DA, Singh BN, Rokahr J 1986 Free fatty acids of human meconium. Biol Neonate 50:16-20

10. Motohiro A, Furukawa T, Yasumoto K, Inokuchi K 1986 Mechanisms involved in acute lung edema induced in dogs by oleic acid. Eur Surg Res 18:50-57

11. Collins JF, de los Santos R, Johanson Jr WG 1986 Acute effects of oleic acid-induced lung injury in baboons. Lung 164:259-268

12. Beilman G 1995 Pathogenesis of oleic acid-induced lung injury in the rat: distribution of oleic acid during injury and early endothelial cell changes. Lipids 30:817-823

13. Julien M, Hoeffel JM, Flick MR 1986 Oleic acid lung injury in sheep. J Appl Physiol 60:433-440

14. Sun B, Curstedt T, Robertson B 1993 Surfactant inhibition in experimental meconium aspiration. Acta Paediatr 82:182-189

15. Folch J, Lees M, Sloane S 1957 A simple method for the isolation and purification of total lipids from animal tissues. J Biol Chem 226:497-509

16. Ranheim T, Gedde-Dahl A, Rustan AC, Drevon CA 1994 Effect of chronic incubation of $\mathrm{CaCo}-2$ cells with eicosapentaenoic acid $(20: 5, \mathrm{n}-3)$ and oleic acid $(18: 1, \mathrm{n}-9)$ on triacylglycerol production. Biochem J 303:155-161

17. Rootwelt T, Odden JP, Hall C, Ganes T, Saugstad OD 1993 Cerebral blood flow and evoked potentials during reoxygenation with 21 or $100 \% \mathrm{O}_{2}$ in newborn pigs. J Appl Physiol 75:2054-2060

18. Medbo S, Yu XQ, Asberg A, Saugstad OD 1998 Pulmonary hemodynamics and plasma endothelin-1 during hypoxemia and reoxygenation with room air or $100 \%$ oxygen in a piglet model. Pediatr Res 44:843-849

19. [No authors] 1998 Babylog 8000 plus Intensive Care Ventilators for Neonates: Instruction for Use software 5.n. Drager Medizintechnik GmbH, Lubeck, Germany, pp 125-126

20. Roske K, Foitzik B, Wauer RR, Schmalisch G 1998 Accuracy of volume measurements in mechanically ventilated newborns: a comparative study of commercial devices. J Clin Monit Comput 14:413-420 
21. Medbo S, Tollofsrud PA, Saugstad OD 1999 Pulmonary hemodynamics in newborn piglets during hypoxemia and reoxygenation: blocking of the endothelin-1 receptors. Pediatr Res 46:514-522

22. Collins LC, Roberts AM, Robinson TW, Joshua IG 1996 Direct effects of meconium on rat tracheal smooth muscle tension in vitro. Pediatr Res 40:587-591

23. Khan AM, Shabarek FM, Kutchback JW, Lally KP 1999 Effects of dexamethasone on meconium aspiration syndrome in newborn piglets. Pediatr Res 46:179-183

24. Holm BA, Notter RH 1987 Effects of hemoglobin and cell membrane lipids on pulmonary surfactant activity. J Appl Physiol 63:1434-1442

25. Wang Z, Notter RH 1998 Additivity of protein and nonprotein inhibitors of lung surfactant activity. Am J Respir Crit Care Med 158:28-35

26. Hall SB, Lu RZ, Venkitaraman AR, Hyde RW, Notter RH 1992 Inhibition of pulmonary surfactant by oleic acid: mechanisms and characteristics. J Appl Physiol 72:1708-1716

27. Taeusch WH, Lu KW, Goerke J, Clements JA 1999 Nonionic polymers reverse inactivation of surfactant by meconium and other substances. Am J Respir Crit Care Med 159:1391-1395

28. Fuchimukai T, Fujiwara T, Takahashi A, Enhorning G 1987 Artificial pulmonary surfactant inhibited by proteins. J Appl Physiol 62:429-437

29. Tollofsrud PA, Solas AB, Saugstad OD 2001 Newborn piglets with meconium aspiration resuscitated with room air or 100\% oxygen. Pediatr Res 50:423-429

30. Hoeck WG, Ramesha CS, Chang DJ, Fan N, Heller RA 1993 Cytoplasmic phospholipase $\mathrm{A}_{2}$ activity and gene expression are stimulated by tumor necrosis factor: dexamethasone blocks the induced synthesis. Proc Natl Acad Sci USA 90:4475-4479

31. Newton R, Kuitert LM, Slater DM, Adcock IM, Barnes PJ 1997 Cytokine induction of cytosolic phospholipase $\mathrm{A}_{2}$ and cyclooxygenase- 2 mRNA is suppressed by glucocorticoids in human epithelial cells. Life Sci 60:67-78

32. Shiue ST, Thrall RS 1991 Effect of corticosteroid therapy on the acute injury and recovery stage of oleic acid induced lung injury in the rat. Exp Lung Res 17:629-638

33. Henderson RD, Fung K, Cullen JB, Milne EN, Marryatt G 1975 Bile aspiration: an experimental study in rabbits. Can J Surg 18:64-69

34. Porembka DT, Kier A, Sehlhorst S, Boyce S, Orlowski JP, Davis Jr K 1993 The pathophysiologic changes following bile aspiration in a porcine lung model. Chest 104:919-924

35. Holm P 1997 Endothelin in the pulmonary circulation with special reference to hypoxic pulmonary vasoconstriction. Scand Cardiovasc J Suppl 46:1-40

36. Michael JR, Markewitz BA 1996 Endothelins and the lung. Am J Respir Crit Care Med 154:555-581

37. Rossi EM, Philipson EH, Williams TG, Kalhan SC 1989 Meconium aspiration syndrome: intrapartum and neonatal attributes Am J Obstet Gynecol 161:1106-1110

38. Falciglia HS 1988 Failure to prevent meconium aspiration syndrome. Obstet Gynecol 71:349-353

39. Dooley SL, Pesavento DJ, Depp R, Socol ML, Tamura RK, Wiringa KS 1985 Meconium below the vocal cords at delivery: correlation with intrapartum events. Am J Obstet Gynecol 153:767-770

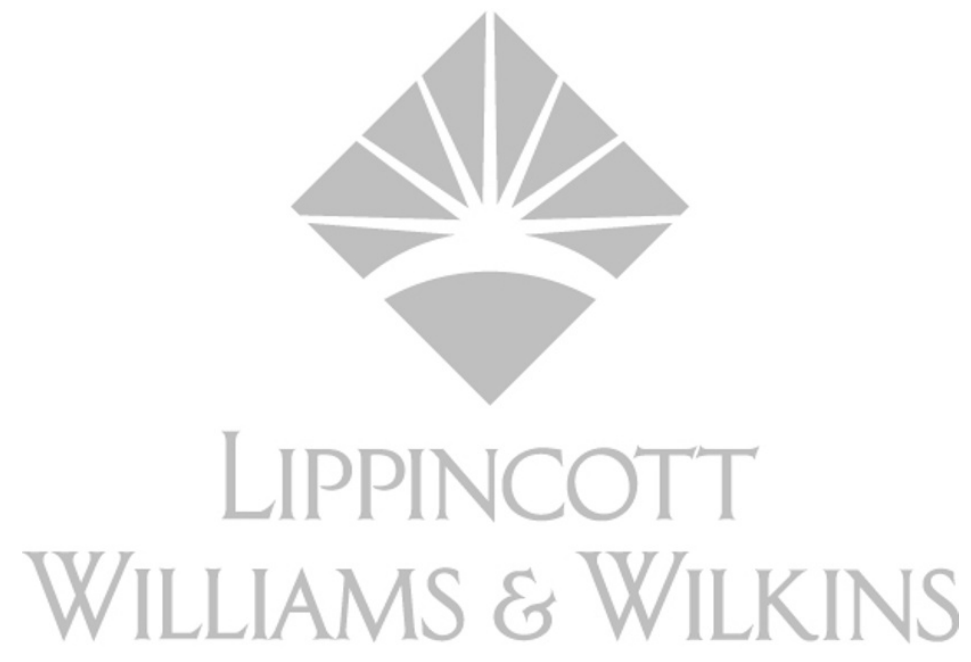

